\title{
Seeking best practice in online learning: Flexible Learning Toolboxes in the Australian VET sector
}

\author{
Ron Oliver \\ Edith Cowan University
}

This paper describes The Flexible Learning Toolboxes Project, a component of the Australian Flexible Learning Framework for the National Vocational Education and Training System 2000-2004 (AFL Framework). The AFL Framework is designed to support the accelerated take-up of flexible learning modes and position Australian VET as a world leader in applying new technologies to vocational education products and services. A Toolbox is a set of learning resources designed for web based delivery in a manner which facilitates customisation and reuse in the National Training Framework, which forms the basis of qualifications and accreditation in the Australian VET sector. The paper describes aspects of the Project and discusses the innovative design approaches that are being used to create quality online learning resources. Examples of several Toolboxes are provided to demonstrate the forms of online learning settings that have been developed for the Australian VET sector.

\section{Introduction}

Online learning environments in higher education are frequently criticised for their failure to make the most of the opportunities afforded by the new technologies (eg. Dehoney \& Reeves, 1999). Too often the design of the settings is constrained by such practical factors as inflexible delivery systems, the need for converged on and off campus settings, and the quest to generate online courses from existing print based materials. Rarely do developers have the opportunity, the direction and the support to plan and build high quality online learning materials. One project in Australia, however, that differs from others in this regard, is the Flexible Learning Toolboxes Project (Australian Flexible Learning Framework, 2001).

The Toolbox initiative is part of the Australian Flexible Learning Framework for the National Vocational Education and Training System 2000-2004 (AFL Framework). The AFL Framework is designed to support the accelerated take-up of flexible learning modes and position Australian VET as a world leader in applying new technologies to vocational education products and services (EdNA VET Advisory Group, 2000). A 
Toolbox is a collection of resources, suggested learning strategies and supporting material for the online delivery of vocational education and training. The learning resources are web based and designed in a manner which facilitates customisation and reuse in the National Training Framework, the basis of qualifications and accreditation in the Australian VET sector.

\section{Flexible Learning in the VET sector}

National and state authorities responsible for VET within Australia have recognized for some years that developing online materials is expensive and best achieved through a collaborative approach (EdNA VET Advisory Group 1999). It was this challenge that prompted the Australian National Training Authority (ANTA) to consider strategies that could motivate and support registered training organisations (RTOs) to embrace modes of flexible delivery for their students. A resource strategy was formulated by which sets of generic and customisable materials could be developed and applied widely throughout the training sector. The intention was to create efficiency and economies of scale though large scale production of learning materials capable of wide acceptance and use. This plan became the ANTA Flexible Toolbox Project which has evolved since 1999 into the Flexible Learning Toolbox Project of today.

In Australia, the mission of ANTA is to "ensure that the skills of the Australian labour force are sufficient to support internationally competitive commerce and industry and to provide individuals with opportunity to maximise their potential" (ANTA, 1998). ANTA's agenda has been "to deliver training more responsively and efficiently and to a wider catchment area" (ANTA, 1998). The Authority recognises that technological advances have been the catalyst for new forms of educational and training communication systems and that the demand for, and supply of vocational education and training is globalising. Consequently it has enacted and sponsored strategies to encourage the VET providers to provide more flexible, technological based, delivery for domestic and international markets. ANTA recognised that implications of technology advances and globalisation required "new ways of creating and customising training material" (Eccles, 1998). The Toolbox initiative was one of ANTA's strategies to encourage development and delivery of more flexible learning materials for the training market - particularly for online learning.

\section{Flexible Learning Toolboxes}

The phrase "Training Package" has a specialised meaning in the Australian VET sector, referring to a nationally endorsed statement incorporating the competency standards, assessment guidelines and 
qualifications relating to training in a particular industry sector. These components are uniform at a national level but allow for a range of flexible training pathways for achievement and assessment.

The introduction of Training Packages within the National Framework in 1998 provided a perfect opportunity for the Australian National Training Authority to explore the concept of Flexible Toolboxes to support learning. In the first instance, any products developed in this setting would have widespread application providing significant economies of scale. Secondly the use of online technologies appeared to provide and promote the many forms of flexibility associated with the delivery of the Training Packages in the national setting.

The Flexible Learning Toolbox Project has carried three main development stages to date, from Series One in 1999 to the recently completed Series Three. Developers bid for funding to build Toolboxes from funding managed by the Flexible Learning Advisory Group (FLAG), a committee with strong interest and expertise in flexible delivery in the VET sector. Teams and consortia work together to develop bids to build online learning resources for qualifications within the national Training Packages. Teams are required to demonstrate strong links with the industry groups and to propose online materials that demonstrate evidence of sound contemporary learning designs and development processes that create materials with high levels of product utility. The following descriptions from the developers' guidelines highlight these aspects of Toolbox design:

\section{a. Toolbox learning designs}

A fundamental requirement of Toolbox resources is the need to exhibit effective teaching and learning approaches. To support this requirement, proponents need to demonstrate their capacity to develop resources with the following features:

- a firm basis in an educational model which recognises an active, constructive role for learners;

- learning activities which engage the learner in active processing of the subject matter rather than mere knowledge acquisition;

- learning settings and tasks that encourage meaningful online communication and interaction (between learners as well as between teachers and learners);

- content resources which are visually attractive, motivating to use and organised logically for ease of navigation; and

- representations of authentic and real life settings in preference to textual descriptions.

\section{b. Toolbox product utility}

A second important consideration concerns product utility characteristics. Toolboxes are expected to allow for wide applicability 
across the target audience for whom they are intended. For this reason they are expected to be flexible, portable to a range of delivery platforms, and readily customised. The following characteristics are desirable:

- the use of readily available non-proprietary development software;

- the use of HTML code where customisation can be anticipated, with more sophisticated development software (eg Flash) reserved for components that are unlikely to be changed;

- the development of platform independent resources which allow for maximum portability to users' delivery platforms;

- avoidance of rigid structuring devices locking the learner into one pathway through the material (although a suggested learning sequence may be desirable); and

- a file and directory structure that facilitates the location of a particular learning segment, or the selection of a single unit (where applicable), as well as the use of the whole Toolbox.

Toolboxes are also expected to be widely accessible. They are expected to operate on client computers running at $300 \mathrm{MHz}$ and guidelines are provided to developers for aligning the Toolboxes with:

- the EdNA metadata standard;

- the W3C content accessibility guidelines (Priority 1); and

- the Preferred Standards Project.

In the three series of Toolboxes to date, approximately 40 Toolboxes have been developed for qualifications across a variety of Training Packages. Extensive quality assurance processes have been developed to monitor and manage the development processes of the various teams which are usually located throughout the country. The quality assurance processes are implemented to ensure a high quality project and include a range of strategies and checks and measures.

In a typical Toolbox Project, developers are invited to submit an Expression of Interest (EOI) for developing a Toolbox to the FLAG Steering Committee who select from among the 100 or so applications approximately 40 projects for which an extended proposal is invited. The EOI process is used to ensure that the selection process leads to a strong blend of qualifications across a variety of Training Packages, that the full scale proposals are presented by teams with the capacity and capability to deliver quality learning products.

From the full scale proposals, around 15 projects are selected for funding, for amounts of around $\$ 250,000$. A comprehensive review process is used to select only the best proposals and successful teams are provided with comprehensive feedback indicating strengths and weaknesses within their plans. The process is overseen by the National Project Managers, a team of 
experts in online learning and flexible delivery within the Office of Employment, Education and Training in Victoria.

A mentoring process accompanies the design and development processes. Mentors are allocated by the National Project Managers to each team. A mentor is a critical friend with extensive experience in the design of effective online learning materials. The mentor works closely with the team throughout the nine months of the process which includes an initial proof of concept waypoint that is used to confirm the success of the planned products. Once the Toolboxes have been completed, they are quality checked by technical experts before being supplied to Australian Training Products, the company supporting their dissemination. Any Registered Training Organisation is able to buy a CD containing the required Toolbox at a nominal fee. The fee providers a license to use the products freely on local servers, an extensive Teachers' Guide to assist in use of the products and, for the most recent series, access to a free Help Desk to facilitate installation and use of the resources. Table 1 provides details of the Toolbox Projects to date and their development periods.

Table 1. Flexible Learning Toolbox series

\begin{tabular}{|l|c|c|}
\hline Toolbox Series & $\begin{array}{c}\text { Number of } \\
\text { Toolboxes }\end{array}$ & Project Period \\
\hline Series One & 12 & $1998 / 1999$ \\
\hline Series Two & 14 & $1999 / 2000$ \\
\hline Series Three & 16 & $2000 / 2001$ \\
\hline Series Four & to be decided & $2001 / 2002$ \\
\hline
\end{tabular}

The extensive quality assurance processes have seen the Toolbox products develop from quite conventional forms in Series One to outstanding examples of online learning in Series Three. The aim of this paper is to exemplify aspects of the educational design practices employed in the Toolbox Projects that have led to the development of these exemplary online learning environments.

\section{Best practice in online learning}

While there are many critics of the quality of much of the online learning development that has taken place to date, there are relatively few examples and instances of high quality products. The high quality products that do appear are often designed for specific discipline needs and are difficult to use as generic exemplars and cases for others to follow. For the first Series of Toolboxes, the lack of exemplars tended to limit the scope of designs and teaching ideas that were used. In subsequent rounds, 
deliberate efforts were made in the specification of the tender guidelines and through the mentoring process to provide guidance and exemplars to encourage and support design strategies that led to the development of high quality online learning settings.

The framework that was used to inform and guide the instructional design process is a component model, described in Table 2, which comprises three elements which represent critical components of any learning settings. In particular, the framework highlights connections and distinctions between the elements which can be made in the design of online learning settings (Oliver, 1999).

Table 2. Framework describing critical elements of online learning settings

\begin{tabular}{|c|l|l|}
\hline $\begin{array}{c}\text { learning } \\
\text { design } \\
\text { elements }\end{array}$ & \multicolumn{1}{|c|}{ description } & \multicolumn{1}{c|}{ examples } \\
\hline $\begin{array}{c}\text { learning } \\
\text { activities }\end{array}$ & $\begin{array}{l}\text { The tasks, problems, } \\
\text { interactions used to engage } \\
\text { the learners and upon which } \\
\text { learning is based }\end{array}$ & $\begin{array}{l}\text { Reading activities, computer based } \\
\text { interactions, simulations, inquiry } \\
\text { tasks, projects, open ended } \\
\text { problems, inquiry tasks, } \\
\text { collaborative tasks }\end{array}$ \\
\hline $\begin{array}{l}\text { learning } \\
\text { resources }\end{array}$ & $\begin{array}{l}\text { The content, information } \\
\text { and resources with which } \\
\text { the learners interact in } \\
\text { completing the tasks }\end{array}$ & $\begin{array}{l}\text { Web pages, readers, textbooks, } \\
\text { computer based tools, Web links, } \\
\text { notes, documents, workplace } \\
\text { manuals, case studies, databases }\end{array}$ \\
\hline $\begin{array}{l}\text { learning } \\
\text { supports }\end{array}$ & $\begin{array}{l}\text { The scaffolds, structures, } \\
\text { motivations, assistances and } \\
\text { connections used to support } \\
\text { learning }\end{array}$ & $\begin{array}{l}\text { Learning guides, discussions, chats, } \\
\text { suggested learning pathways, } \\
\text { mentors, buddies, workplace } \\
\text { trainers }\end{array}$ \\
\hline
\end{tabular}

The framework provides a means to isolate and study the various elements within learning settings and suggests emphases which can be made in the instructional design process. Contemporary learning theories posit that the forms of learning design most appropriate to higher education are those based on constructivist learning principles. The above framework takes on particular and discrete forms when applied this way.

\section{a. learning activities}

The learning activities play a critical role in determining the scope and extent of learning outcomes in any educational setting (Wild \& Quinn, 1997). They determine how the learners will engage with the course materials and the forms of knowledge construction that will take place. Contemporary thinking suggests that the activities must be active and engaging (eg. Wild \& Quinn, 1997). They need to engender cooperative 
and collaborative activities among the cohort and in doing so must provide opportunities for reflection and articulation (eg. Jonassen \& Tessmer, 1996; Collis, 1998). The activities must provide the purpose and the context for learners to deal with the content and information (Duffy \& Cunningham, 1996).

Fundamental to the notion of knowledge construction is an active role for the learner in which there is encouragement and reason to act in a self directed fashion. Characteristic of these approaches to learning are settings and activities which see learners assuming much of the responsibility for themselves in terms of what is learned and how it is learned (eg. Duffy \& Cunningham, 1996). The optimal conditions for self directed learning however appear to exist in settings where learners work collaboratively with others in ways that promote social interactions and articulation (eg. Vygotsky, 1978).

In conventional settings, the typical forms of learning activity are often content oriented, for example, reading textbooks and attempting small consolidation and practice activities. Such tasks provide little scope for student ownership of the learning and demand little self direction and decision making. In contrast, constructivist activities tend to be based around tasks that are open ended, problem based and ill-structured (eg. Boud \& Feletti, 1997). These tasks form the basis of the students' learning and their successful completion is used as a measure of the learning achieved.

\section{b. learning resources}

Choosing and developing content is seen by many teachers as the most important step in creating online learning environments. This is reflected in the resulting materials which often have a content focus (eg. Dehoney \& Reeves, 1999). It is sometimes estimated that online teachers spend $90 \%$ of their planning and development creating content and online learning resources. Contemporary thinking suggests that the content can, and should, assume a far lesser role in the design process. It is often argued that learners need to be exposed to content that provides them with perspectives from a multitude of sources (eg. Herrington \& Oliver, 1995). The materials need not all be online. The use of conventional materials along with electronic sources can provide the diversity often required. Previously, designers created course materials where the content was rigidly organised and presented to the learners in a strict sequence. Settings that promote knowledge construction recognise that learners need to be able to access resources in a variety of ways and such settings tend to provide flexibility and choice in resource use (eg. Lebow, 1993). 
Duschatel (1997) argues that content also needs to be chosen in a fashion which provides authentic examples and contexts. This argument is very much in line with situated learning principles (eg. Brown, Collins \& Duguid, 1989). The move to outcomes based and competency based education is a reflection of this form of thinking. In such instances, the content is presented as a means to an end rather than an end in itself and it is the learner who must make most of the choices about which material to use and how to use it. There are many ways in which these principles and ideas can be implemented in online settings. Perhaps the best strategy to deal with this is to consider content as a resource for learning rather than the focus of learning.

\section{c. learning supports}

The third and final critical design element from the framework is that of learning supports. Flexible and online learning environments need learning supports to be designed as integral parts of the learning process. The support is necessary to guide learners and to provide a feedback mechanism which is responsive and sensitive to their individual needs (eg. McLoughlin \& Oliver, 1998).

A number of writers have developed strong frameworks to describe the ideal forms of support required for online learning environment and in each case, there is usually a strong argument made for an active and involved teacher (eg. Laurillard, 1993). The role of the teacher however, tends to be defined as that of a coach and facilitator in place of the more didactic style often assumed. In contemporary settings, this form of learning support is called scaffolding in recognition of the way in which it helps to build knowledge and is then removed as the knowledge construction occurs.

Conventional settings tend to provide quite structured forms of support. For example, through the use of learning guides and learning pathways, organized communications channels and processes. In settings supporting knowledge construction the optimal forms of learner support are scaffolds that are adaptive and flexible to meet the needs of learners. In such settings, teachers act as facilitators and coaches and provide a range of flexible strategies and processes to provide learners with feedback and assistance appropriate to their needs.

The three elements of learning environments described in the component framework (Oliver, 1999) are necessarily connected. It is not uncommon for learning activities to be also learning resources and learning supports. Our research and inquiry, however, suggest that the best opportunities for knowledge construction occur in settings where these elements are relatively distinct and discrete. The experiences from the use of this 
framework with the Flexible Learning Toolboxes have supported this contention. There are now numerous Toolboxes that provide exemplars of high quality learning settings and where the deliberate distinction of the elements in the design process have contributed significantly to the development of high quality learning environments.

\section{Designing quality online learning activities}

The National Training Packages which form the basis of all Toolbox developments are nationally endorsed training materials which describe an integrated set of nationally endorsed competency standards and assessment guidelines. By their very nature Training Packages seek to develop learners' competencies and it is this feature that makes the selection and design of learning activities an important and critical component of the online learning settings. In more general terms, Training Packages are very much about learning how, as distinct from, learning about.

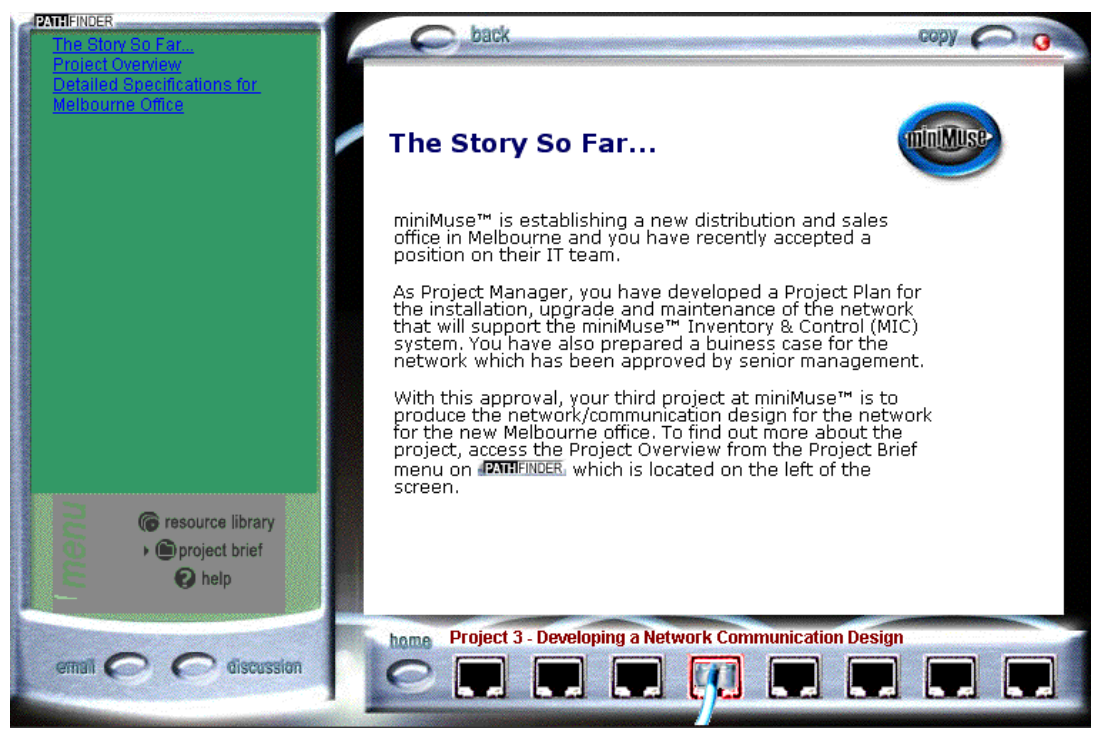

Figure 1a: Network Engineering Toolbox: The choice of the contexts for learning activities plays an important role in the scope and extent of the learning that is achieved. In the Series 3 Network Engineering Toolbox, each of the units is presented in the form of an individual task for which they will need to learn and apply new knowledge. The task itself is reflective of the purpose of the unit of study. The tasks are very much like those students will meet in real life and in the workplace. The authenticity gives relevance and meaning to the information that is acquired in the process of completing the task. 


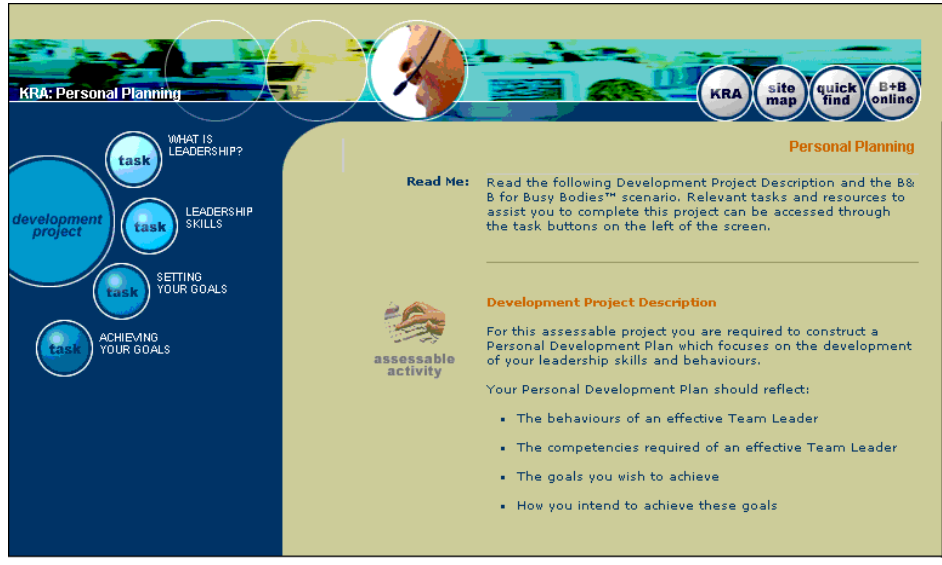

Figure 1b: Call Centres III \& IV: In the Series 3 Call Centres Toolbox, students are presented with a variety of tasks which form the basis of their learning. The tasks require students to plan and formulate their courses of action. The outcomes from the tasks are not set and provide students with opportunities to work within their own contexts. The ill-structured tasks reflect the real world rather than a sanitised classroom. The decision making and the information seeking associated with the solution are powerful enhancements to the learning.

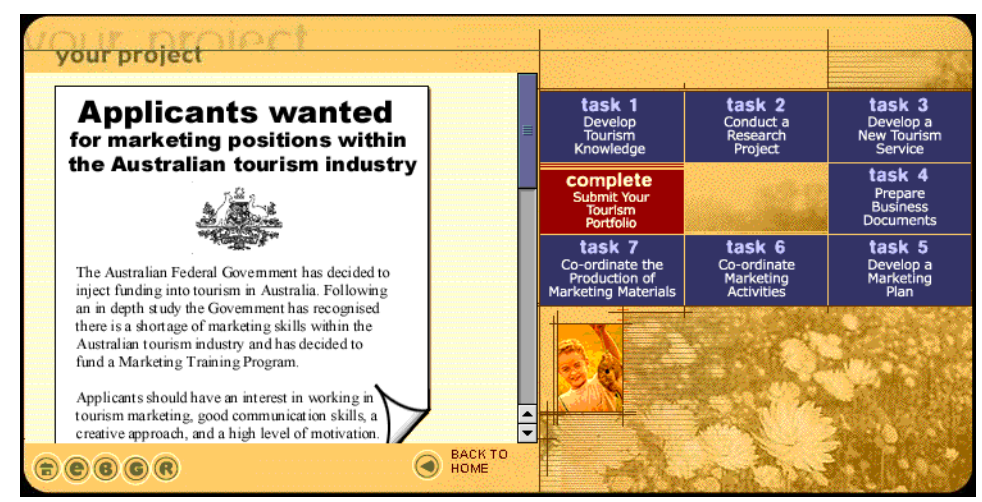

Figure 1c: Tourism Toolbox: In many Toolboxes the various units are presented in the context of an overall setting. In the Tourism Toolbox, students assume the roles of entrepreneurs and as they complete the various activities they work through the complete process of developing a tourism product as if they were working in the field and undertaking a consulting role. This comprehensive anchoring process provides connections between the various units and helps the learning to build as the learner progresses.

Figure 1: Flexible Learning Toolboxes: Learning activity exemplars 
In the design of learning activities for Toolboxes, developers are encouraged to consider the competencies being developed and the forms of learner activity that will support this development. This approach to instructional design takes the emphasis away from content as the organising framework for learning and places it squarely with learner activity. The design of activities that can develop competency requires a high degree of knowledge and understanding on the part of the designer. The activities need to engage the learners, to encourage reflection and articulation and to promote higher order thinking. Activities which lack these elements rarely help students to learn in any meaningful way. Typical learning designs that have informed the development of Toolbox learning activities have included problem based learning (eg. Boud \& Feletti, 1997), case based learning (eg. Land \& Green, 2000) and inquiry based learning (eg. Magnussen, Ishida \& Itano, 2000).

The forms of activities that can provide this form of cognitive activity tend to be open ended and ill structured. They require students to demonstrate problem solving and planning (eg. Duffy \& Cunningham, 1996). They involve elements of self direction and metacognition. And above all they need to be set in contexts that reflect the intended application of the knowledge. They require high degrees of authenticity and relevance (eg. Shaffer \& Resnick, 1999). Good designers can create learning activities with these attributes across all levels of learning, for students in the entry level units for Certificates and for students completing the last units in their Diplomas. Figure 1 provides some examples of these characteristics among the Flexible Learning Toolboxes. In many instances the Toolboxes display many of the desirable attributes in novel and innovative forms.

\section{Selecting quality online learning resources}

A common approach in the development of online settings is through content centred approaches where course content and its delivery is used as the basis of the learning materials. This approach is limited in the learning it can support by virtue of the fact that learners often have no explicit purpose or reason to interact. Such settings tend often to be lacking in context and and relevance.

In the Flexible Learning Toolboxes, designers are encouraged to select and design learning resources in response to learners' needs. These needs arise from the learning activities they are given and the resources matched to the forms of learning outcomes being sought. The consequence of choosing resources based on the needs of learning activities creates a number of advantages for the learning environment. These advantages stem from the fact that the resources can be organised in meaningful ways for access and retrieval and that developers can use existing resources without specifically having to tailor them for their needs. The resources 
can be taken from actual settings and can be documents and and manuals from workplace settings.

The separation of resources from learning activities that is encouraged in the Toolbox development supports their customisation and reuse. The use of consistent metatags and organisational strategies that support disaggregation also provides advantages for storage in repositories and the concept of reusable learning objects. Figure 2 provides some examples of the strategies used to present learning resources among the various Toolboxes. It demonstrates ways in which the resource organisations employed are able to support student learning and the transfer of this learning to the workplace.

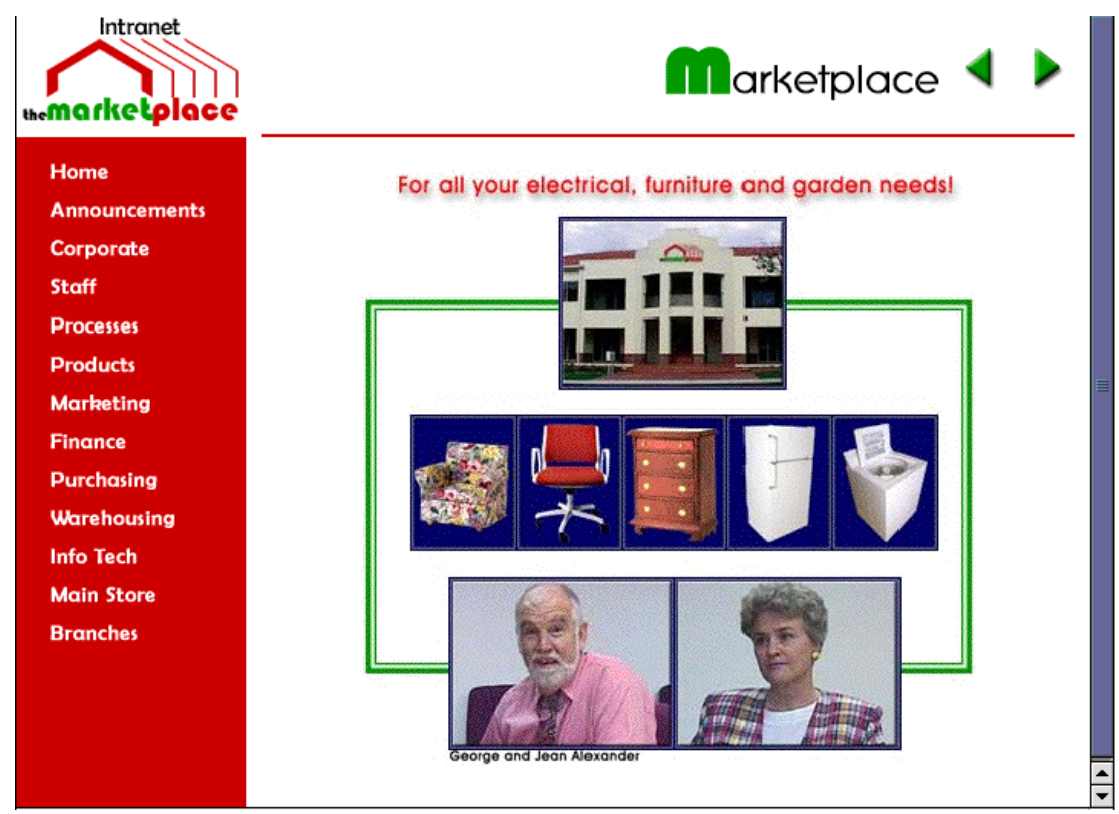

Figure 2a: Systems Analysis Toolbox: The separation of instruction and information within many of the Toolboxes creates opportunities for an array of information sources. In the Systems Analysis Toolbox, learners are provided with a sample Intranet as a source for information for the various learning activities. Learners in the workplace are able to use resources from their own settings in place of the Intranet that is provided. The use of resources from the workplace and from simulated settings provides many opportunities for learner engagement and reflection. It removes much of the need to create resources specifically for the online setting and supports and encourages the use and reuse of resources as learning objects. 


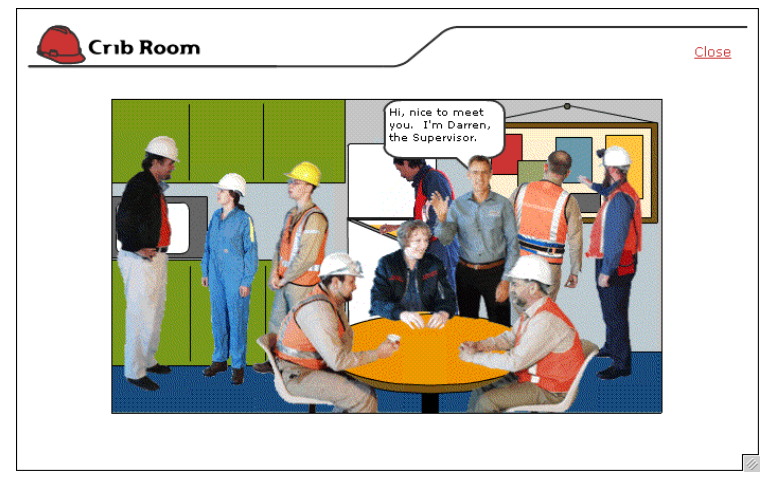

Figure 2b: Mining Toolbox: The use of resource libraries and organised information sources enables the designers to create settings where learners are able to choose the resources they use and to view material from a variety of perspectives. Learners can be encouraged to deal critically with information and to make informed choices as to which information to use and when they have sufficient for their purposes. In the Mining Toolbox learners are able to review the impressions of the workers through an innovative lunchroom scenario. The learner clicks on the various workers who offer a range of forms of information to the learner.

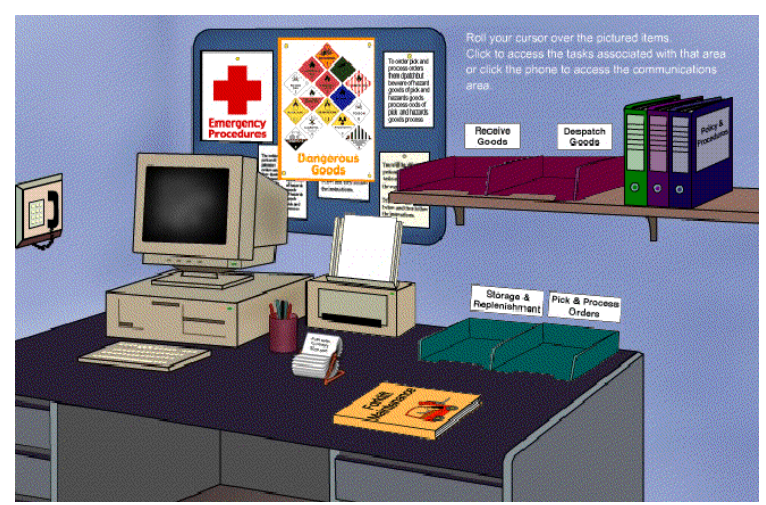

Figure 2c: Warehousing Toolbox: When information and instruction are separated, designers can use a variety of strategies to organise and represent the information. In the Warehousing Toolbox, learners view a simulated office setting as a means for accessing information. The office contains such information as procedure and policy manuals, booklets, charts, order forms etc. By working in the simulated environment, learners are able to make connections between the online learning materials and those in their workplace settings. They learn to access information in ways that have direct transfer to their workplace setting.

Figure 2: Flexible Learning Toolboxes: Learning resources examples 


\section{Designing quality online learning supports}

Many of the early online learning developments attempted to create reduced roles for teachers and tutors as a means to create economies of scale and delivery. More recently online learning settings have been characterised by high levels of teacher support through the use of discussion boards and other forms of online communication. Most designers recognise the need to provide supports and guidance for learners in online settings and include an array of tasks for this purpose. In the Flexible Learning Toolboxes, designers have been encouraged to explore ways to provide feedback and support for learners through processes that promote students' self directed learning. The intention is to provide strategies for support that reduce the need for direct teacher intervention and activity while still ensuring learners have access to the forms of help needed to progress.

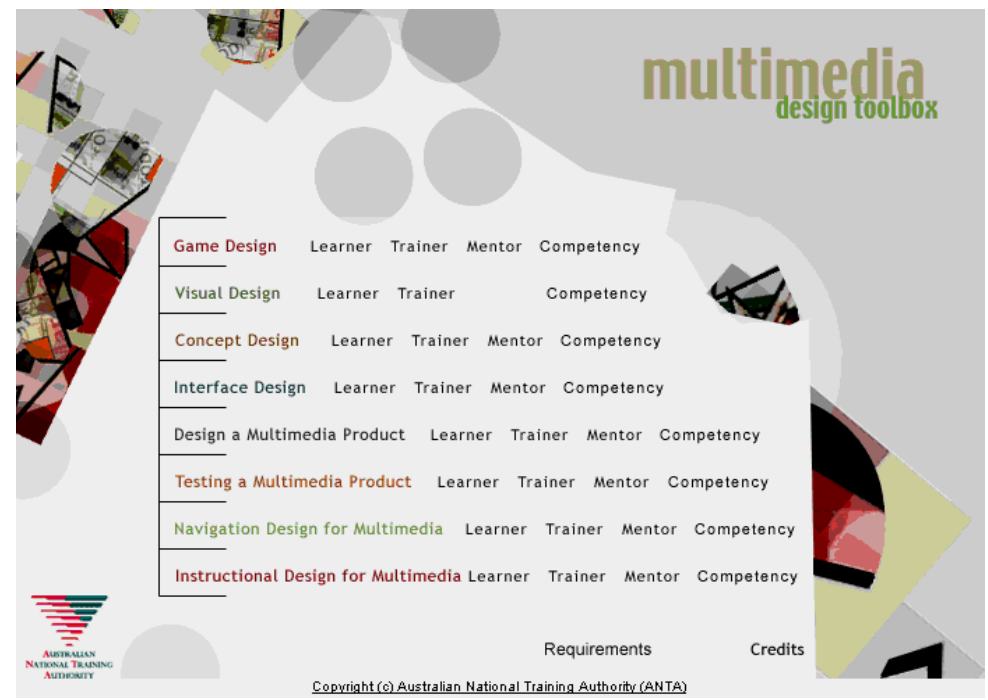

Figure 3a: Multimedia Design Toolbox: Some of the best supports for online learning can be learners themselves, their colleagues and work associates. The design of online learning settings that recognise and encourage this form of assistance provides many opportunities for the learning. Students can gain more focused and relevant help and there is far less demand placed on the teacher. In the Multimedia Toolbox, learners work with buddies, other students, and mentors, workplace associates with appropriate skills levels. This support encourages and motivates learners as well as providing strong forms of assistance. The Toolbox provides a raft of tasks and activities which are supported by the joint actions of the student and others, apart from the teacher. 
The Inititial Reference Interview

Repeat or paraphrase the question

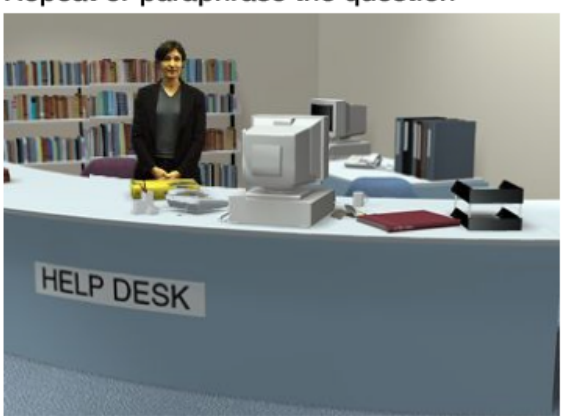

Click on each item to hear the tone of voice you might use to restate a question asked by a client.

- $\underline{\text { Helpful }}$

- Astonished

- Bored

- Patronising

Topic info MENU

Figure 3b: Library and Information Services Toolbox: Many Toolboxes make use of the multimedia and interactive capabilities of the online environment to provide learners with computer based resources to support their learning. For example in the Library and Information Services Toolbox students are presented with a number of multimedia resources, an example of which is library staff dealing with customers. The students are able to view the interactions and to make judgments on the appropriateness of the staff responses and behaviours. The samples provided seek students' input and provide feedback and guidance based on their answers. Such resources provide strong support for the forms of learning sought.

The forms of learning support that have been included in many of the Flexible Learning Toolboxes are those which provide scaffolds for the students and which can be faded as the learning occurs. The strategies that have been used include the use of buddies and mentors as human supports, innovative bulletin borads and postings as electronic supports and adpative guides and online supports that students can use at their will when required. In most instances, the Toolboxes enable teachers a number of choices and options in the forms of support they will use with their students, a factor which recognises the importance of the teacher in the online setting while accommodating the needs of the individual and self directed learners. Figure 3 provides some examples of the forms of learning supports used in the Toolbox projects. 


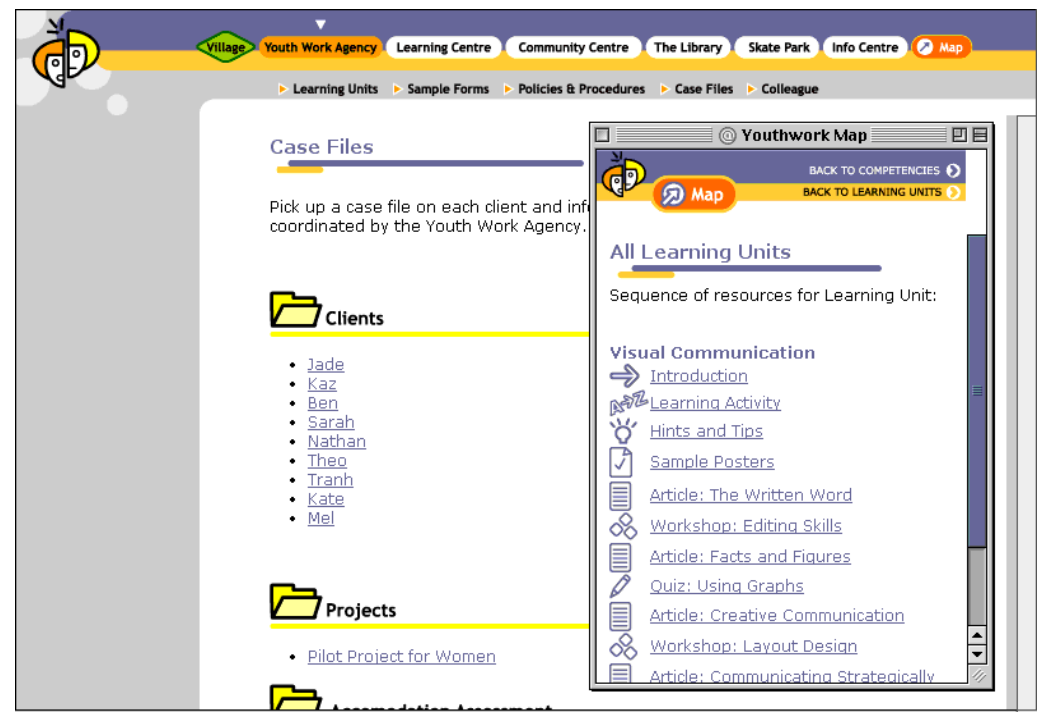

Figure 3c: Youthwork Toolbox: Learning scaffolds are supports provided for the learners that enable them to choose the extent and scope of the assistance they require. The assistance is provided in such a way as to support student learning beyond what might be possible when students are left to their own devices completely. As the student develops expertise and skill, the amount of support taken can be reduced, a strategy that helps learners to move forward under their own devices. In the Youthwork Toolbox, students can gain assistance from a Learning Map, a suggested learning pathway which prompts learners as they undertake the self directed tasks that form the basis of the package.

Figure 3: Flexible Learning Toolboxes: Learning support strategies

\section{Summary and conclusions}

The Flexible Learning Toolbox Project described in this paper provides some strong examples of learning designs that might reasonably be presented as examples of best practice in online learning. The original aims of the Project were derived from a firm vision of the future of flexible learning in the VET sector and the capacity of contemporary technologies to realise the vision. This paper has demonstrated the commitment and forward thinking nature of the EdNA VET Advisory group who initiated the Project in its early days and has described the evolution of the growth of flexible learning support and development in the VET sector across several years to the current initiatives of the Australian Flexible Learning Framework. The Flexible Learning Toolbox Project is just one example of the pioneering work in flexible learning in the Australian VET sector. 
This paper has described aspects of the Toolbox Project and the philosophies that have underpinned its activities. In particular the paper has described strategies associated with the design and development of online learning materials that have led to development of some high quality learning products for the sector. Online samples of the Toolboxes discussed in this paper and information about all the Toolboxes from Series One, Two and Three can be viewed on the Web at http: / / www.flexiblelearning.net.au/toolbox/

All teacher sand designer who are interested and/or involved in the design and development of online learning settings will find some useful examples and ideas within the various products of the Toolbox Project. In particular, the Project provides some sound practical designs for online learning that supports knowledge construction. As the Project continues into the coming years, it will continue to evolve and is likely to remain as an exemplar of best practice in the design and development of online flexible delivery materials for higher education.

\section{References}

ANTA (1998) A bridge to the future: Australia's National Strategy for Vocational Education and Training 1998-2000,. Australian National Training Authority, Brisbane.

Australian Flexible Learning Framework (2001). http: / / www.flexiblelearning.net.au/ [verified 13 Aug 2001]

Boud, D. \& Feletti, G.(1997). Changing Problem-based Learning. Introduction to the Second Edition. In D. Boud \& G. Feletti (Eds.), The Challenge of Problem-based Learning (2nd ed., pp. 2-16). Kogan Page: London.

Collis, B. \& Oliver, R. (1999) Preface in B. Collis \& R. Oliver (Eds), Proceedings of the 11" World Conference on Educational Multimedia, Hypermedia and Telecommunications. Association for the Advancement of Computers in Education, Virginia.

Eccles. C., (1998) A New Training Culture for Australia: The Right Stuff. Australian National Training Authority, Brisbane.

EdNA VET Advisory Group. (1999) Flexible Learning for the Information Economy: A Framework for National Collaboration in Vocational Education and Training 20002004. Australian National Training Authority, Brisbane.

Collis, B. (1998). WWW-based environments for collaborative group work. Education and Information Technologies, 3, 231-245.

Dehoney, J., \& Reeves, T. (1999). Instructional and social dimensions of class web pages. Journal of Computing in Higher Education, 10(2), 19-41. 
Duffy, T. M., \& Cunningham, D. J. (1996). Constructivism: Implications for the design and delivery of instruction. In D. H. Jonassen (Eds.), Handbook of research for educational communications and technology (pp. 170-198). New York: Simon and Schuster.

Duschatel, P. (1997). A web-based model for university instruction. Journal of Educational Technology Systems, 25(3), 221-228.

Flexible Learning Toolbox Project (2001).

http: / / www.flexiblelearning.net.au/toolbox/ [verified 13 Aug 2001]

Herrington, J . \& Oliver, R. (1995). Critical characteristics of situated learning: Implications for the instructional design of multimedia. In J. Pearce \& A. Ellis (Eds) Learning with Technology, ASCILITE'95 Conference Proceedings, (pp 395-403). Melbourne: ASCILITE. [verified 13 Aug 2001]

http:/ / www.ascilite.org.au/conferences/melbourne95/smtu/abstracts/herrington.html

Jonassen, D. \& Reeves, T. (1996). Learning with computers: Computers as cognitive tools. In D. Jonassen (Ed.), Handbook of Research for Educational Communications and Technology (pp. 693-719). New York: MacMillan Library Reference.

Jonassen, D. \& Tessmer, M. (1996-97). An outcomes based taxonomy for instructional systems design, evaluation and research. Training Research Journal (2), 11-46.

Kearsley, G. (1998). Educational technology: A critique. Educational Technology, 4, 47-51.

Land, S. \& Greene, B. (2000). Project-based learning with the World Wide Web: A quantitative study of resource integration. Educational Technology Research and Development, 48(1), 45-67.

Laurillard, D. (1993). Rethinking University Teaching: A Framework for the Effective Use of Educational Technology. London: Routledge.

Lebow, D. (1993). Constructivist values for instructional systems design: Five principles toward a new mindset. Educational Technology, Research and Development, 41(3), 4-16.

Magnusson, L., Ishida, D., \& Itano, J. (2000). The impact of the use of inquiry-based learning as a teaching methodology on the development of critical thinking. Journal of Nursing Education, 39(8), 360-364.

McLoughlin, C. \& Oliver, R. (1998). Scaffolding higher order thinking in a telelearning environment. Ottmann, T. \& Tomek, I. (Eds). Proceedings of EdMedia/Ed-Telecom 98 World Conference on Educational Multimedia and Hypermedia $\mathcal{E}$ World Conference on Educational Telecommunications. Virginia: AACE. (pp 977983).

Oliver, R. (1999). Exploring strategies for on-line teaching and learning. Distance Education, 20(2), 240-254. 
Shaffer, D. \& Resnick, M. (1999). Thick authenticity: New media and authentic learning. Journal of Interactive Learning Research, 10(2), 195-215.

Wild, M. \& Quinn, C. (1997). Implications of educational theory for the design of instructional multimedia. British Journal of Educational Technology, 29(1), 73-82.

Vygotsky, L. (1978). Mind in Society. Cambridge MA, Harvard University Press.

Dr Ron Oliver, Professor of Interactive Multimedia

School of Communications and Multimedia, Edith Cowan University

2 Bradford St, Mt Lawley WA 6050, Australia

Email r.oliver@cowan.edu.au 